\title{
Pessoas com deficiência e políticas de saúde no Brasil: reflexões bioéticas
}

\author{
Persons with disabilities and Brazilian healthcare policies: \\ thoughts about bioethics
}

Liliane Cristina Gonçalves Bernardes ${ }^{1}$

Izabel $M$ aria $M$ adeira de Loureiro $M$ aior ${ }^{1,2}$

Carlos Humberto Spezia ${ }^{3}$

Tereza Cristina Cavalcanti Ferreira deAraujo ${ }^{4}$

${ }^{1}$ Coordenadoria Nacional para Integração da Pessoa Portadora de Deficiência, Secretaria Especial dos

Direitos Humanos,

Presidência da República.

Esplanada dos M inistérios,

Bloco T/Anexo II/210.

70064-900 Brasília DF.

liliane.bernardes@sedh.gov.br

${ }^{2}$ Faculdade de M edicina,

UniversidadeFederal do

Rio dejaneiro.

${ }^{3}$ Secretaria de Gestão do

Trabalho eEducação na

Saúde, M inistério da Saúde.

${ }^{4}$ Universidade de Brasília

(UnB).
Abstract Thepurpose of this articleis to analyze the dilemma of allocation of public funds to the healthcare of people with disabilities in Brazil from a bioethical standpoint. The concept of disability and the legal framework are presented; the question of budgetary constraints and theoretical bioethics references about this issue are discussed; and the role of Bioethics of Protection and Bioethics of Intervention is stressed. It is concluded that, because of their vulnerability, people with disabilities should be protected by the state and funds must be allocated to guarantee their access to healthcare services. However, in spite of the existing legal basis, the actual destination of public funds to people with disabilities still depends on other factors, among others social and political participation of the disabled persons themselves in the negotiation of healthcare policies. Key words Bioethics, Persons with disabilities, Allocation of funds, $\mathrm{H}$ ealthcare policies
Resumo 0 artigo propõe reflexões, à luz da bioética, acerca do dilema da alocação de recursos públicos para a assistência à saúde das pessoas com deficiência no Brasil. Para tanto, o conceito de deficiência e o marco legal brasileiro de assistência às pessoas com deficiência são apresentados; faz-se uma análise sobre a escassez de recursos; discutem-se referenciais teóricos atinentes e destaca-se 0 aporte da bioética de proteção e da bioética de intervenção. Conclui-seque, em razão desua vulnerabilidade, as pessoas com deficiência devem ser protegidas pelo Estado e recursos devem ser empregados para garantir seu acesso aos serviços de saúde. Enfatiza-se, também, que apesar da previsão legal já existente, a efe tiva destinação de recursos depende de outros fatores, tais como a participação sociopolítica das pessoas com deficiência na "pactuação" das políticas de saúde.

Palavras-chave Bioética, Pessoas com deficiência, Recursos em saúde, Políticas de saúde 
Introdução

Segundo a Organização das Nações Unidas ${ }^{1}$, há cerca de 600 milhões de pessoas com deficiência no mundo, sendo que $80 \%$ vivem em países em desenvolvimento. Estas pessoas estão dentre as mais estigmatizadas, mais pobres e que têm os níveis mais baixos de escolaridade de todos os cidadãos mundiais, caracterizando violação de direitos humanos universais. No Brasil, dados do Censo Demográfico de $2000^{2}$ revelaram que 24,6 milhões de indivíduos se reconhecem com algum tipo de deficiência, o que corresponde a 14,5\% da população.

É imprescindível salientar que pessoas com de ficiência constituem um grupo heterogêneo que reúne, em uma mesma categoria, indivíduos com vários tipos de deficiência física, sensorial, intelectual e mental. Por conseguinte, as ações de saúde voltadas para esse segmento têm que considerar um mosaico de diferentes necessidades. $M$ ais do que isso, cuidados e acompanhamento devem ser iniciados precocemente, tão logo seja diagnosticada alguma lesão potencialmente causadora de incapacidades. Do contrário, o desenvolvimento e a qualidade de vida destas pessoas podem ficar irreparavelmente comprometidos, afetando sua inserção social, seja no mercado de trabalho, seja na vida em comunidade. Evidentemente, tal perspectiva denatureza preventiva epromocional está condicionada à al ocação de recursos, o que exige reflexões e debates visando à fundamentação e ao planejamento de políticas públicas neste setor.

Em bioética, concepções como principialismo, utilitarismo, bioética de proteção e bioética de intervenção oferecem aportes para a análise da situação das minorias. Sendo assim, o presente trabaIho considera que essas correntes podem mediar a abordagem de dilemas éticos suscitados pela assistência a pessoas com deficiência e propõe focalizar a problemática da alocação de recursos, que envolve, de um lado, a escassez de insumos para atender as crescentes demandas no campo em geral da saúde e, de outro lado, as necessidades especiais daqueles acometidos por agravos incapacitantes.

\section{D eficiência ebioética}

Defato, a evolução conceitual induzida pelas transformações sócio-históricas e culturais impôs ajustes contínuosà compreensão sobre deficiência. Historicamente, as pessoas que possuíam algum tipo de deficiência eram afastadas do convívio social e as ações direcionadas a esse grupo eram basicamente assistencialistas e engendradas por motiva- ção religiosa ou caritativa. Esta situação ainda é presente, mas vem se tornando menos freqüente, em parte, como resultado das atitudes e comportamentos das próprias pessoas com deficiência. $\mathrm{Ou}$ seja, identifica-se uma mudança paradigmática em quea visão preconceituosa eexcludenteem relação aos "deficientes" cede à percepção das competências e da participação social destas pessoas.

Também éimportante assinalar quea noção de deficiência pressupõe uma multiplicidade de conceitos, quese situam do plano técnico ao plano existencial, tais como: defeito, doença, incapacidade, limitação, exclusão e sofrimento, o que dificulta sua delimitação precisa. Considerando tal dificuldade, al guns autores ${ }^{3}$ insistem na necessidade de se avaliar tanto fatores etiológicos, patológicos eclínicos, como também a experiência da deficiência em nível pessoal ecoletivo (família ecomunidade). Sugerem que a al teração da função pessoal seja compreendida da seguintemaneira: uma doença ou agravo causa um defeito que gera uma incapacidade que se traduz em uma deficiência com repercussões psicológicas e sociais.

Outrossim, é relevante mencionar que, sob a ótica individual, existem pessoas com lesões quenão experimentam a deficiência, assim como existem pessoas com expectativas de lesões que se consideram deficientes. N esse sentido, a distinção entre lesão edeficiênciaécrucial, poisalesão éuma expressão biológica isenta de sentido, ao passo quea deficiênciaéum fenômeno sociológico queserevela pelas inúmeras barreiras sociais restritivas - por exemplo, baixa escolaridade e reduzida taxa de empregabilidade - à expressão das capacidades das pessoas com deficiência. D esse ponto devista, a experiência da deficiência não resulta delesões, mas do ambiente social adverso à singularidade. Em outras palavras, comumente tida como propriedade natural do ser, a incapacidade é um produto social ${ }^{4}$.

Cabe ressaltar que o conceito de deficiência assumido pelo Estado tem impacto direto na construção de políticas públicas de saúde, poiséo principal critério de inclusão ou exclusão de ben eficiários dessas políticas. No caso do Brasil, o Decreto no 3.298, de 20/12/1999, definiu deficiência como "toda perda ou anormalidade de uma estrutura ou função psicológica, fisiológica ou anatômica que gere incapacidade para o desempenho da atividade, dentro do padrão considerado normal para 0 ser humano" 5 .

Em síntese, é possível depreender que, seja no âmbito privado, seja no âmbito coletivo, a deficiência traz à tona muitos dilemas que requerem análise bioética, como as práticas vinculadas a contextos culturais específicos, como o infanticídio de 
crianças com deficiência em algumas comunidades indígenas no Brasil, passando pelo seu abandono em países da África, até o financiamento e a implementação de políticas públicas.

\section{Principialismo bioético}

Na década de 1970, Beauchamp e Childress ${ }^{6}$ introduziram uma proposta teórica em bioética, posteriormente conhecida como principialismo, que busca reunir em quatro princípios universais o ferramental básico para a discussão de dilemas éticos: autonomia, beneficência, não-maleficência ejustiça.

A primeira ação organizada que resgata a autonomia das pessoas com deficiência foi o M ovimento deVida Independente, surgido em Berkeley, Califórnia, na década de 1960. Um dos princípios do movimento era afirmar a capacidade da pessoa com deficiência em administrar a sua vida como qualquer outra pessoa, tomar decisões, se fazer representar e ter voz própria nas questões que lhe dizem respeito eque serelacionam aos seus interesses. Esse movimento, portanto, é anterior à publicação por Potter ${ }^{7}$ de seu livro Bioethics: brigde to the future, considerado marco inicial da bioética como campo do conhecimento, e também precede o trabalho desenvolvido por Beauchamp e Childress 6 .

De acordo com o principialismo, o respeito à autonomia implica reconhecer a capacidade de autogoverno da pessoa (compreensão, raciocínio, deliberação e escolha independentes). A ação autônoma deve ser intencional, com entendimento e sem influências controladoras que determinem sua forma de agir. N esse sentido, as pessoas com deficiência estão potencialmente sob risco de ter sua autonomia cerceada, poisa deficiência écomumente confundida com incapacidade de julgamento e decisão, gerando nas pessoas não deficientes a premissa paternalista de tomar decisões que a pessoa com deficiência seria capaz de realizar por si mesma. Embora a lesão possa gerar algum tipo de incapacidade, isso não significa necessariamente prejuízo no julgamento ou na habilidade de decidir. Uma noção deturpada da autonomia em condições de deficiência acaba por chancelar tratamento superprotetor, infantilizador e autoritário por parte de profissionais de saúde, cuidadores efamiliares. Muitas vezes, cria-se uma relação na qual a pessoa com deficiência éo pólo frágil eo não-deficiente passa a agir como fonte de poder.

M uitos daqueles que adotam esta postura paternalista argumentam que estão aplicando o princípio da beneficência, que, de acordo com Beauchamp e Childress ${ }^{6}$, significa buscar fazer o bem.
Entretanto, diversas pesquisas sobre comunicação em saúde apontam as limitações e eventuais prejuízosdeuma interação profissional-paciente em que apenas o conhecimento técnico é legitimado, em detrimento de outras fontes de informação, para sustentar e orientar as práticas assistenciai $\mathbf{s}^{8,9}$.

A não-mal eficência significa não infligir danos intencionalmenteetambém evitar que el es venham a ocorrer. Segundo este princípio, tanto o diagnóstico da deficiência quanto os cuidados específicos devem ocorrer precocemente para assegurar o de senvolvimento global da criança e de pessoas com alguma lesão potencial mente causadora de deficiência. 0 diagnóstico precoce da deficiência auditiva, por exemplo, possibilita interven ção imediata, oferecendo condições para o desenvolvimento psicológico, educacional e social, favorecendo um prognóstico mais favorável ${ }^{10}$.

$\mathrm{Na}$ atenção à saúde, o princípio da justiça está fortemente relacionado à justiça distributiva, isto é, à responsabilidade da sociedade em distribuir eqüitativamente as cargas e os ben efícios do cuidado com a saúde 6 . A "igualdade para todos" é al go comumente apregoado pelos governos, embora raras sejam as situações nas quais se possa realmente definir de qual tipo de igualdade está se falando. Devido à diversidade humana, é extremamentedifícil estabelecer critérios justos para distribuição igualitária de bens primários e de oportunidades. As desigualdades motivam a busca por justiça e o fato de alguns possuírem muito pouco enquanto outros têm muitos bens gera preocupações morais por mai or eqüidade ${ }^{11}$.

0 direito à saúde como um direito humano básico é questionado por alguns autores, como Engel hardt ${ }^{12}$, teórico estadunidense, que alude a dois tipos de "Ioteria", aos quais os indivíduos estão expostos: a loteria natural e a loteria social. A loteria natural é uma expressão usada para identificar diferenças na sorte resultantes de forças naturais: al guns nascem com saúde, outros com graves enfermidades e deformidades. Assim, aqueles que ganham na loteria natural não precisarão de assistência à saúde durante a maior parte de sua vida. Já a loteria social expressa mudanças na sorte ocasionadas pela ação de pessoas. Para Engelhar$\mathrm{dt}^{12}$, a loteria natural cria desigual dades e coloca os indivíduos em desvantagem, sem criar a obrigação moral secular direta de ajudar aquel es que têm necessidades fazendo uso da força do Estado para a redistribuição de energias e recursos privados.

Em contraste a tal posicionamento, vários autores defendem maior ação estatal para a diminuição das desi gualdades sociais, inclusive no acesso a serviços desaúde. Segundo Sgreccia ${ }^{13}$, o Estado deve 
se colocar em uma perspectiva de subsidiariedade em relação aos menos favorecidos. Entretanto, em um contexto de burocratização e busca de eficiência, é freqüente a opção por uma solução descompromissada, como a concessão de algum tipo de "ajuda-subsídio", ou simplesmente a institucionalização das pessoas que têm deficiência em vez de se oferecer recursos e meios que propiciem, tanto quanto possível, autogestão e inclusão social.

\section{Bioética de proteção}

Demodo semelhante, a bioética de proteção ${ }^{14,15}$, gerada na América Latina e pensada para a realidade dos países da região, defende o Estado como protetor dos mais vulneráveis. Basicamente, tratase de uma ética da assimetria, na qual há dois pólos diferentes: um fraco, quenecessita de apoio, incapaz de enfrentar a vida sem ajuda, e outro com poder $e$ energia suficientes para repartir e assumir a responsabilidadedecuidar do fraco. Além de assimétrica, a ética da proteção é também coletiva, eo único ente político capaz de assumir funções de proteção coletiva é o Estado. Retomando Kottow ${ }^{16}$, é possível reforçar que A ética de proteção é por antonomásia uma ética da assimetria, assim como o é, embora em outro sentido, a ética da libertação. A figura moral da proteção se compõe de uma instância forte - o pai, 0 Estado - e outra fraca que tem que ser protegida - os enfermos, os pobres, os discriminados, os débeis.

Para a ética da proteção, a justiça, queéuniversal, deve ser aplicada às necessidades específicas dos mais susceptíveis, focalizando as ações sociais a favor dos mais necessitados. Isto significa assumir que aqueles que têm menos recursos deverão receber mais proteção do Estado. Uma de suas proposições é a possibilidade de impor restrições à autonomia em certas condições. Logo, um programa público de saúde poderá ser imposto com sacrifício parcial da autonomia pessoal, se as conseqüências desse programa se mostrarem comprovadamente efetivas em prol do bem comum da população. Não se trata de totalitarismo, mas da restrição de certos aspectos da autonomia que possam interferir no programa sanitário. Este é o caso das campanhas de vacinação em massa.

\section{Bioética de intervenção}

Também de origem latino-americana, a bioética de intervenção amplia a questão da justiça para um enfoque global, introduzindo na discussão as diferenças econômicas e sociais entre países "centrais" e "periféricos". Ela está alicerçada no conceito de eqüidade, compreendido como a busca em se "tratar desigualmente os desiguais", em defesa dos interesses e direitos históricos das populações dos "países periféricos". N esse sentido, esse modelo teórico propõe a análise de dilemas tais como autonomia versus justiça/eqüidade; benefícios individuais versus benefícios coletivos; individualismo versus solidariedade ${ }^{17}$.

O princípio deutilidade, inicialmentedescrito (em 1768) por Bentham ${ }^{18}$, éum dos referenciais teóricos da bioética de intervenção. Ele pode ser entendido como aquele princípio que aprova ou desaprova qualquer ação, segundo a tendência de aumentar ou de diminuir a felicidade da pessoa cujo interesse está em jogo. Uma medida de governo está em conformidade com o princípio da utilidade quando a tendência que tem de propiciar a felicidade for maior que qualquer tendência no sentido de diminuí-la.

De acordo com esse referencial, levando-se em conta a escassez de recursos disponíveis, a tomada de decisão na esfera pública e coleti va deve priorizar o maior número de pessoas, durante o maior espaço de tempo possível, almejando as melhores conseqüências, mesmo que em prejuízo de certas situações individuais, com al gumas exceções pontuais $^{19}$. D essa forma, resguardados os direitos humanos, o bem-estar da maioria é o fator determinante da alocação de recursos públicos.

\section{Recursos em saúde e eqüidade}

Em saúde, políticas públicas promovem eqüidade ao transferir recursos de contextos mais abastados para os mais carentes. Porém, como esclarece Stiglitz ${ }^{20}$, no al cance desta meta interpõe-seum conflito entre eficiência e eqüidade das políticas de bemestar social em uma economia demercado. O u seja, a manutenção da eficiência é importante para o crescimento econômico dos países ea mel horia das condições de vida de seus cidadãos depende de quão eficientementea economia opera aumentando a renda nacional. Em geral, para se al cançar uma maior eqüidade, pode ser necessário que algum montante deeficiência tenha queser sacrificado. Portanto, cabe à sociedade definir, em relação às políticas de distribuição de renda e à alocação de recursos, quanto deverá ser transferido dos mais ricos para os mais pobres e do quanto de eficiência ela está disposta a abrir mão. Dessa forma, ao se promover eqüidade, énecessário considerar a perda de eficiência envolvida no processo e buscar mecanismos que facilitem sua inserção na agenda governamental e neutralizem as mais diversas resistências.

Vários fatores se opõem à eqüidade. Um deles é o fato de que grupos com maior poder de pres- 
são e negociação na arena decisória serão os maiores prejudicados com a implementação de políticas redistributivas. Outro fator que merece destaque é que este modelo econômico mostra-se perversamente excludente em relação às pessoas com deficiência. Em geral, os investimentos necessários para incluí-las na força de trabalho de um país é erroneamente visto como economicamente inviável. Muitas vezes, a cultura da discriminação confunde capacidade diferenciada com in eficiência.

Segundo Abberley ${ }^{4}$, em um sistema capitalista, acumulam-se as contradições em torno da deficiência. De um lado, atribui-se improdutividade a esse grupo de pessoas em razão da deficiência e, de outro, considera-se fundamental torná-las produtivas para manter a eficiência do sistema, mas caso isso não se mostre economicamente viável, buscase reduzir ao máximo a interrupção na acumulação de capital e persistir na maximização dos lucros, em detrimento da inclusão social.

Quanto à sociedade brasileira, é possível introduzir o problema da alocação de recursos para a saúde partindo dos conceitos de igualdade e justiça tal como propõe Amartya Sen ${ }^{21}$. A poiados nesse autor, Gonçalves et al. ${ }^{22}$ qualificam como iníquas as desigualdades entre ricose pobres na saúde, pois são desigualdades injustas e não inerentes aos seres humanos. No Brasil, as persistentes desigualdades, no que tangem aos direitos humanos fundamentais, exibem adistância entreo queestabeleceo texto constitucional eseu cumprimento efetivo ejusto.

\section{Legislação brasileira epolítica nacional para a pessoa com deficiência}

Inegavel mente, a Constituição de 1988 trouxeavanços em relação às questões sociais, de garantia de direitos ede cidadania ${ }^{23}$. Todavia, no quese refereàs pessoas com deficiência, as decisões foram remetidas à regulamentação posterior e, ainda que o marco legal tenha formalizado direitos básicoseessenciais, mantiveram-se idéias de caráter assistencialista - as quais já estavam cristalizadas na sociedade - e que constituem entrave ao processo de inclusão social e participação no desenvolvimento do país $5^{5}$.

Chama atenção que, no texto constitucional, ao se tratar da Saúde, utiliza-se somente a expressão "recuperação", citada no artigo 196, a qual pode estar ou não associada ao atendimento integral dos cidadãos com deficiência, e apenas na seção da Assistência Social, artigo 203, é que surgem os termos "habilitação", "reabilitação" e "promoção" de sua integração à vida comunitária ${ }^{23}$.

A Lei Orgânica da Saúde (Lei no 8.080/90) dita as características do Sistema Ú nico de Saúde(SUS), em especial o caráter de acesso universal, com gestão descentralizada ${ }^{24}$. Esta lei não trata de qualquer atenção especializada à saúde daqueles que apresentam deficiência. Por seu turno, a Lei Orgânica da Assistência Social ( Lei no 8.742/93) regulamenta as ações relativas ao atendimento de habilitação e reabilitação, tendo como público-alvo famílias com renda inferior a meio salário mínimo ${ }^{24}$. Também trata do benefício assistencial não-contributivo destinado às pessoas que tenham deficiência severa a ponto de incapacitá-las para a vida independente epara o trabal ho, se a renda familiar per capita for inferior a um quarto do salário mínimo - o Benefício de Prestação Continuada ${ }^{24}$.

A Lei $n-7.853 / 89^{5}$ eo Decreto no $3.298 / 99^{5}$ correspondem aos principais documentos normativos garantidores da cidadania das pessoas com deficiência. Os princípios, as diretrizes, os objetivos e os instrumentos da Política Nacional para Integração da Pessoa Portadora de D eficiência tratam da ação governamental e das responsabilidades de cada setor, determinando pleno acesso à saúde, à educação, à habilitação e reabilitação profissionais, ao trabalho, à cultura, ao desporto, ao turismo e ao lazer, bem como de normas gerais de acessibilidade nos espaços físicos, nos transportes, na comunicação einformação eno quetange às ajudas técnicas.

As Leis no $10.048^{5}$ e n ${ }^{0} 10.098^{5}$, ambas de 2000, estabelecem as normas gerais e critérios básicos para a promoção da acessibilidade das pessoas com deficiência ou com mobilidade reduzida. Essas leis foram regulamentadas pelo D ecreto $\mathrm{n}=5.296 / 2004^{5}$, que dispõe sobre 0 atendimento prioritário a pessoas com deficiência, trata da implementação da acessi bilidade arquitetônica eurbanística, do acesso aos meios de transporte, do acesso à informação e à comunicação, da tecnologia assistiva eestabelece o Programa Nacional de Acessibilidade e 0 Comitê de Ajudas Técnicas.

Entendendo, portanto, que a Constituição $\mathrm{Fe}$ deral não mencionou claramente as responsabilidades do setor da saúde no tocante ao público de pessoas com deficiência, tanto a Lei o $7.853 / 89^{5}$ como o Decreto no 3.298/995 estabeleceram extensa relação de obrigações para o setor público de saúde. Assim a lei determina ações preventivas, de diagnóstico e encaminhamento precoce para tratamento; programas específicos de prevenção de acidentes; criação de redes de servi ços especializados em reabilitação e habilitação, garantia de acesso aos estabelecimentos de saúde, públicos e privados, recebendo tratamento adequado, garantia de atendimento domiciliar de saúde para pessoa com deficiência grave e programas de saúde de- 
senvolvidos com a participação da comunidade para estimular a integração social do grupo.

Já no decreto de regulamentação, além de todas as determinações citadas, são introduzidos artigos detal hando conceitos e ações a serem imple mentadas, constituindo-se numa política geral de assistência integral à saúde e reabilitação, da qual também fazem parte a dispensação deórteses, próteses, bolsas coletoras e todas as demais ajudas técnicas emedicamentos. Acrescenta-seainda a re alização de estudos epidemiológicos para produzir informação acerca da ocorrência de deficiências e incapacidades, com vistas a subsidiar a tomada de decisão.

M ais recentemente, a política nacional de saúde para as pessoas com deficiência, aprovada no Conselho Nacional de Saúde e publicada pelo M inistério da Saúdena Portarian ${ }^{\circ} 10.060 / 2002^{25}$, trouxe o detal hamento para as ações tanto no Sistema Ú nico de Saúde e nas diversas instâncias governamentais, como nas relações intersetoriais e nas de parceria com as organizações não-governamentais da sociedade. A proposição central desta política é "reabilitar a pessoa portadora de deficiência na sua capacidade funcional e no desempenho humano - de modo a contribuir para a sua inclusão plena em todas as esferas da vida social" - e "proteger a saúde deste segmento populacional, bem como prevenir agravos que determinem 0 aparecimento de deficiências".

Particularmenterefletindo sobre disponibilidade de recursos, é interessante citar mais dois artigos da Constituição Federal23. 0 artigo 23 , inciso II, que estabelece competência comum da União, dos estados, do Distrito Federal e dos municípios "para cuidar da saúde eassistência pública, da proteção egarantia das pessoas portadoras de deficiência" e 0 artigo 24, inciso XIV, o qual assevera que compete a todos os níveis da organização do Estado legislar concorrentemente sobre "a proteção e integração social das pessoas com deficiência". Ambos os artigos ressaltam o caráter intergovernamental e integrador das medidas adotadas pelo poder público e também evidenciam que ter competência pressupõe aportar recursos oriundos das receitas arrecadadas em cada nível de governo ${ }^{26}$.

\section{Alocação derecursos para a assistência à saúde das pessoas com deficiência}

Conforme anteriormente apresentado, em relação ao marco legal brasileiro, não há dúvida que dispositivos constitucionais e infraconstitucionais, ape sar de sua apresentação fragmentada, visam a pro- teger os direitos fundamentais da pessoa com deficiência, entendendo o direito de acesso aos serviços de saúde como um direito fundamental. Esse posicionamento é respaldado por documentos internacionais de proteção aos direitos humanos, como a Declaração Universal sobre Bioética e Direitos Humanos, homologada pela Unesco ${ }^{27}$ em 2005, ea Convenção sobre os Direitos da Pessoa com Deficiência, adotada pela O NU ${ }^{28} \mathrm{em} \mathrm{2006.0}$ primeiro documento já foi assinado pelo Brasil e o segundo, de caráter vinculante, encontra-se em análise no Congresso Nacional com vistas a sua ratificação com equivalência à emenda constitucional. A Convenção da O NU ${ }^{28}$ imputa obrigações aos EstadosParte decaráter moral, ético, político eeconômico, que se encontram, dentre outros, nos artigos da saúde e da reabilitação do público destinatário.

Ao longo do tempo, a agenda governamental brasileira não tem contemplado suficientemente as questões da pessoa com deficiência. Em setembro de 2007, o governo federal lançou o Programa de Direitos de Cidadania das Pessoas com Deficiência que corresponde a uma série de medidas voltadas para esse segmento, com maior aporte de recursos financeiros, o que denota maior visibilidade do tema na arena decisória. Entretanto, apesar de positivas, em geral as medidas anunciadas estão mais direcionadas à execução e ao aceleramento de itens já previstos pelo dispositivo legal e em programas de governo. Isto mostra que é preciso mais articulação para que leis e medidas sejam instrumentos efetivos de mudança social.

Vale esclarecer que, a partir dessa recente agenda, a política de saúde do segmento será introduzida no Pacto pela Saúde, importante instrumento de priorização e pactuação/negociação de recursos no âmbito tripartite. Constatada a demanda reprimida de cerca de 1.042 .000 pessoas por concessão de órteses e próteses (tecnologias assistivas) , a ação foi considerada prioritária e faz parte do Programa, no qual estão destinados, até 2010 , recursos adicionais de $R \$ 680.000 .000,00$.

As pessoas com deficiência no Brasil encontram-se inseridas em um contexto social bastante diverso daquelas que vivem em países desenvolvidos. Por essa razão, as reflexões bioéticas acerca da alocação de recursos para esse grupo devem se pautar pela discussão teórica desenvolvida na América Latina em meio aos seus contrastes e peculiaridades.

A bioética anglo-saxônica, centrada em conflitos individuais e permeada pela preponderância do princípio da autonomia sobre o princípio da justiça, não parece plenamente apta a traduzir a realidade social dos países latino-americanos. $M$ as, 
segundo Kottow ${ }^{16}$, a bioética latino-americana não pode descartar completamente 0 discurso hegemônico vindo defora, sob pena deficar desconectada dos centros de decisão evulnerável aos embates que ameaçam o bem comum, especialmente dos vulneráveis. No entanto, é necessário desenvolver um discurso próprio que reflita sobre as práticas de saúde, em especial as públicas, e forneça orientação quanto à tomada de decisão.

A bioética de proteção respalda a alocação de recursos para os vulneráveis. Para Kottow ${ }^{16}$, o seu conceito de vulnerabilidade, bem como 0 de susceptibilidade formulado por $\mathrm{O}^{\prime} \mathrm{N}$ eill ${ }^{29}$ ou de incapability proposto por Sen ${ }^{21}$, têm em comum o fato dedesignarem à sociedadeo dever de proteção, exercido por meio de instituições e práticas especificamente projetadas para atenuar, reduzir e, se possível, eliminar incapacidades. A proteção, portanto, poderia ser considerada como um princípio bioético, fundamentado na responsabilidade da sociedade em proteger os suscetíveis e incapacitados. Ao Estado cabe, portanto, o papel de protetor das pessoas com deficiência, especialmente daquelas em situação de pobreza, dada a situação de duplo risco social em que seencontram. Diante dessa assertiva, deve-selembrar o posicionamento deEngelhardt ${ }^{12}$, para quem, em razão de nossas limitações morais seculares, não se pode aceitar a uniformidade de pacotes básicos deassistência à saúde. Para ele, deve ser respeitado o princípio do consentimento ea assistência à saúde obedecer à máxima: "Dê àqueles que precisam ou desejam assistência à saúde aquela pela qual ele, vocês e outros estejam dispostos a pagar ou oferecer gratuitamente". Ora, essa visão conflitante com a ética de proteção foi enfrentada, no Brasil, por meio deleis que, como demonstrado anteriormente, garantiram às pessoas com deficiência 0 acesso universal aos serviços de saúde, à integralidade e à igual dade na assistência.

Mas, é admissível cogitar que, como o Brasil vive em uma economia de mercado, a decisão por maior eqüidade possa gerar uma diminuição de eficiência em sua economia, o que afetaria a todos. Contudo, segundo Oliveira ${ }^{30}$, a possibilidade de financiar oportunidades sociais - políticas epidemiológicas, serviços de saúde, facilidades educacionais - é surpreendentemente possível em países pobres. Em síntese, a realização ea execução deum programa adequado de oportunidades sociais estão muito mais relacionadas a opções valorativas do que à riqueza do país. Ou seja, na esfera dos serviços públicos em saúde, não se pode aceitar 0 discurso que apregoa a falta de opção governamental decorrente da escassez de recursos.

\section{Consideraçõesfinais}

No cenário brasileiro, destacam-se os avanços na esfera da legislação vigente; contudo, tais iniciativas não asseguram que de fato os cidadãos estão protegidos. M erecem melhor análise outros elementos que interferem na destinação de recursos públicos para a assistência à saúde: o papel da economia de mercado e a insuficiência do orçamento do Estado.

Outrossim, carecem de mais exame os interesses de grupos influentes sobre a tomada de decisão dos police-makers, sobretudo no que se refere à escolha das prioridades para recebimento de recursos. Ainda nesse nível, é válido ponderar que cada vez mais novos atores sociais alteram o jogo de forças hegemônicas, a exemplo da atuação de grupos organizados que reúnem pessoas com deficiência eseus consel hos de defesa de direitos. I ndubitavelmente, também devem participar dessa mudançarepresentantes políticos elíderes governamentais, cuja emancipação el egitimidade são condições primordiais para o enfrentamento das partilhas de recursos sanitários.

Em síntese, o enfoque bioético constitui contribuição significativa para reflexões sobrealocação de recursos no setor da assistência à saúde das pessoas com deficiência. N otadamente, a bioética ou o princípio da proteção e a bioética de intervenção indicam a premência de atitudes políticas e podem minimizar a fragilidade dos oprimidos e excluídos, na medida em que balizam análises e debates em prol deferramentas de ação social mais equânimes ejustas. É mister também não esquecer que, com o envelhecimento acentuado e acelerado da população brasileira, limitações físicas e psíquicas severas certamente atingirão um contingente cada vez maior de cidadãos, tornando inadiável este debate ético.

\section{Colaboradores}

LCG Bernardes colaborou no desenvolvimento do trabalho e na redação do texto, IM M L M aior participou da concepção, elaboração e redação do trabalho, CH Spezia auxiliou no levantamento de dados e TCCF de Araujo foi orientadora do projeto durante o Curso de Especialização em Bioética da UnB e colaborou na redação do texto. 


\section{Agradecimentos}

À Secretaria Especial dos Direitos Humanos pelo apoio para participação no Curso de Especialização em Bioética da Cátedra Unesco de Bioética da UnB.

\section{Referências}

1. Organização das Nações Unidas. Follow-up to the World Summit for Social Development and the twenty-fourth special session of the General Assembly: emerging issues: "Mainstreaming disability in the development agenda". [acessado 2008 jan 28]. Disponível em: http://www.un.org/disabilities/documents/reports/e-cn5-2008-6.doc

2. Instituto Brasileiro de Geografia e Estatística. Censo Demográfico 2000. Características Gerais da População. Resultados da Amostra. Rio de Janeiro: IBGE; 2003.

3. Barton L, Oliver M. Introduction: The birth of disability studies. In: Barton L, Oliver M. Disability studies: past, present and future. Leeds: The Disability Press; 1997.

4. Abberley P. The limits of classical social theory in the analysis and transformation of disablement. In: Barton L, Oliver M. Disability studies: past, present and future. Leeds: The Disability Press; 1997.

5. Brasil. Coordenadoria Nacional para Integração da Pessoa Portadora de Deficiência. Acessibilidade. Brasília: Secretaria Especial dos Direitos Humanos; 2005.

6. Beauchamp T, Childress J. Principles of biomedical ethics. New York: Oxford: Oxford University Press; 1979.

7. Potter VR. Bioethics: bridge to the future. Englewood Cliffs, New Jersey: Prentice Hall; 1971.

8. Barbosa ACAS, Araujo TCCF. Pré-consulta e consulta na prática assistencial hospitalar. Mudanças 2007; 14(2):205-214.

9. Sliwa JA, M akoul G, Betts H. Rehabilitation-specific commnunication skills training: improving the physician-patient relationship. Am. J. Phys. M ed. Rehabil. 2002; 81(2):126-132.

10. Rabinovich K. Avaliação da audição na criança. In: Lopes Filho O, editor. Tratado de fonoaudiologia. São Paulo: Roca; 1997. p. 265-283.

11. Rawls J. U ma teoria da justiça. São Paulo: Martins Fontes; 2002.

12. Engelhardt HT. Fundamentos de bioética. $2^{\underline{a}}$ ed. São Paulo: Loyola; 2004.

13. Sgreccia E. M anual de bioética. II - Aspectos médicosociais. $2^{\mathrm{a}}$ ed. São Paulo: Loyola; 2004.

14. Schramm FR, Kottow M. Principios bioéticos en salud pública: limitaciones y propuestas. Cad Saúde Pública 2001; 14(4):949-956.

15. Schramm FR. A bioética da proteção em saúde pública. In: Fortes PAC, Zoboli ELCP, organizadores. Bioética e saúde pública. São Paulo: Loyola; 2003.

16. Kottow M. Bioética de proteção: Considerações sobre o contexto latino-americano. In: Schramm FR, Rego S, Braz M, Palácios M, organizadores. Bioética: riscos e proteção. Rio de Janeiro: Fiocruz; 2005. p. 29-44.
17. Garrafa V, Porto D. Bioética, poder e justiça: por uma ética de intervenção. 0 mundo da saúde 2002; 26(1):6-15.

18. Bentham J. U ma introdução aos princípios da moral e da legislação. São Paulo: Abril; 1974.

19. Garrafa V. Da bioética de princípios a uma bioética interventiva. Bioética 2005; 13(1):125-134.

20. Stiglitz JA. Economics of the public sector. New York: Norton Books; 1988.

21. Sen AK. Igualdade de quê? D esigualdade reexaminada. Rio de Janeiro: Record; 2001.

22. Gonçalves ER, Albuquerque GL, Erdmann AL, Ramos FRS, Amadigi FR. Reflexões sobre igualdade, justiça e alocação de recursos na saúde: o olhar da bioética para os dilemas de uma sociedade iníqua. Online Brazilian Journal of Nursing [periódico na Internet]. 2007 6(2). [acessado 2007 nov 10]. Disponível em: http:// www.uff.br/objnursing/index.php/nursing/rt/printer Friendly/j.1676-4285.2006.490/226

23. Brasil. Constituição: República Federativa do Brasil. Brasília: Centro Gráfico do Senado Federal; 1988.

24. Lima NM. Legislação federal básica na área da pessoa portadora de deficiência. Brasília: Secretaria Especial dos Direitos Humanos, Coordenadoria Nacional para Integração da Pessoa Portadora de Deficiência; 2007.

25. Brasil. M inistério da Saúde. Secretaria de Atenção à Saúde, Departamento de Ações Programáticas Estratégicas. $M$ anual de legislação em saúde da pessoa com deficiência. Braślia: Editora do Ministério da Saúde; 2006.

26. Quaresma R. Comentários à legislação constitucional aplicável às pessoas portadoras de deficiência. In: Teperino, M P, organizador. Comentários à legislação federal aplicável às pessoas portadoras de deficiência. Rio de Janeiro: Forense; 2001. p. 1-22.

27. Unesco. Declaração Universal sobre Bioética e Direitos Humanos. [acessado 2008 jan 26]. Disponível em: http://www.bioetica.catedraunesco.unb.br/htm/ X\%20-\%0htm/documentos/declaracaojulho 2006.pdf

28. Organização das $\mathrm{N}$ ações Unidas. Convenção sobre os Direitos as Pessoas com Deficiência. [acessado 2008 jan 26]. Disponível em: http://www.prsp.mpf. gov.br/cidadania/dpesdef/onu.pdf

29. O'Neill O. Towards justice and virtue. Cambridge: University of Cambridge Press; 1996.

30. Oliveira AAS. Bioética de intervenção e macroalocação de recursos sanitários. U niversitas Face 2005/2006; 2(2), 3(1):27-39.

Artigo apresentado em 25/02/2008

Aprovado em 28/08/2008 